\title{
What's new in respiratory infections and tuberculosis 2008-2010
}

\author{
Jeremy S Brown, ${ }^{1}$ Marc C I Lipman, ${ }^{2}$ Heather J Zar ${ }^{3}$
}

${ }^{1}$ Department of Medicine, Centre for Respiratory Research, University College Medical School, Rayne Institute, London, UK

${ }^{2}$ Centre for Respiratory Medicine, Royal Free Hospital, University College Medical School, London, UK

${ }^{3}$ Department of Paediatrics and Child Health, Red Cross War Memorial Childrens Hospital, University of Cape Town, Cape Town, South Africa

\section{Correspondence to} Jeremy S Brown, Centre for Respiratory Research, Department of Medicine, University College Medical School, Rayne Institute, London WC1E 6JJ, UK; jeremy.brown@ucl.ac.uk

Received 21 March 2011 Accepted 23 March 2011 Published Online First 17 April 2011

\section{ABSTRACT}

Over the past few years there have been an increasing number of research articles published in Thorax on respiratory tract infections (including tuberculosis) affecting children and adults. Although these articles cover a wide variety of areas, several broad themes can be discerned. These include greater interest in viral respiratory infections (partially stimulated by the recent influenza A pandemic), improved characterisation of who is at risk of community-acquired pneumonia and mycobacterial infection, research into better diagnostics and attempts to develop new or improved scoring scales for a range of respiratory infection syndromes. There have also been a limited number of articles on how to manage patients with respiratory infection, including describing the efficacy of prevention by vaccination. Overall, there has been a discernible emphasis on transferring advances in clinical science to actual clinical practice, with several papers using molecular methodologies or measuring levels of cytokines or other potential biomarkers to improve diagnostic accuracy in patients with lung infection. There have also been manuscripts linking specific pathogen genotypes to infection phenotype, an area that is likely to be increasingly important in explaining some of the variations in severity between patients with respiratory infection. However, many questions remain on the optimum strategies for the management and prevention of pneumonia, bronchiectasis and tuberculosis, and there remains a strong need for further clinical research in order to make substantial improvements in the management of patients with lung infection.

Since January 2008 there have been $\sim 75$ major research articles published in Thorax related to respiratory infections, mainly, but not exclusively, concerning community-acquired pneumonia (CAP) and tuberculosis (TB). In this review we summarise the main messages and potential impacts on clinical care for some of these articles, and briefly discuss future areas for research into respiratory infection. Although the articles represent a wide variety of research topics and methodologies, many of the articles can be grouped into a number of broad themes which we have used to form the structure of this review.

Over the past decade a major worldwide health concern has been the effects of respiratory viral epidemics, including avian influenza, severe acute respiratory distress syndrome (SARS; caused by a coronavirus) and most recently pandemic H1N1 influenza. The H1N1 pandemic first became apparent in the spring of 2009, and appears to have started in Mexico due to a triple reassortment of porcine $\mathrm{H} 1 \mathrm{~N} 1$ strains resulting in transmission from pigs to humans of a strain with human pandemic potential. ${ }^{1}$ A serological survey in the UK demonstrated rapid spread of pandemic H1N1 in younger age groups, with approximately one in three children infected by September 2009 in some UK regions. ${ }^{2}$ In contrast, there was no increase in the same time period in the proportion of older adults (aged $\geq 45$ years) seropositive for $\mathrm{H} 1 \mathrm{~N} 1$ infection, probably due to pre-existing immunity from exposure in earlier outbreaks. ${ }^{2}$ The current H1N1 pandemic has stimulated an extraordinary amount of scientific and public interest, resulting in $>1500$ articles on PubMed in $<2$ years and considerable media comment. This interest has been reflected by two articles and two editorials in Thorax on pandemic H1N1. ${ }^{3-6}$ Fajardo-Dolci et al described the clinical background to fatal cases from early in the Mexican H1N1 epidemic, ${ }^{3}$ and this was discussed by Dunning et al in an accompanying editorial which provided a useful overview of the clinical considerations with pandemic H1N1. ${ }^{4}$ Nguyen-Van-Tam described the risk factors associated with death for patients with H1N1 in the UK. ${ }^{5}$ An abnormal chest radiograph or raised C-reactive protein (CRP) level on admission were markers for poor outcome, and, in common with studies from other countries, obesity, asthma or other pre-existing co-morbidities were all associated with a higher mortality. In a reversal of the normal pattern of mortality for seasonal influenza, 59\% of patients who died were previously healthy. One of the strongest risk factors was pregnancy, with an OR for death of 6.2 in univariate analysis. Previous influenza pandemics have been characterised by second and third waves of infection in subsequent years, and the potential for recurrent $\mathrm{H} 1 \mathrm{~N} 1$ was discussed in a prescient editorial by Thickett et al just before a resurgence of $\mathrm{H} 1 \mathrm{~N} 1$ infection in the UK during late 2010. This third wave had a significant impact on use of intensive care resources and resulted in a further 411 deaths in the UK, close to the combined total of 474 deaths during the first and second waves (Health Protection Agency statistics). Experience with previous pandemics suggests that pandemic H1N1 may become a common circulating endemic influenza strain. How this will affect the existing pattern of seasonal influenza causing excess deaths mainly in the elderly and patients with co-morbidities rather than the young remains to be seen.

Mortality after viral respiratory infections is often due to concurrent bacterial pneumonia, and two papers have emphasised the association between viral and bacterial lung infection. Jennings et al performed a comprehensive survey of the incidence of respiratory viral infection in 304 
patients presenting with CAP in New Zealand using viral culture, serology, PCR and immunofluroescence. ${ }^{7}$ The results showed that $29 \%$ of cases were associated with viral infection and, in contrast to previous publications, rhinovirus was as common as influenza infection and a significant number of patients were infected with adenovirus or respiratory syncytial virus. Forty-six per cent of patients with viral infection had coinfection with a bacterial pathogen, mainly (as expected) Streptococcus pneumoniae. Interestingly co-infection of rhinovirus with $S$ pneumoniae had an OR of 9.95 (albeit with very wide CIs) for severe CAP, defined using the CURB65 score. Why viral infection is so closely associated with bacterial pneumonia is multifactorial, and probably includes viral effects on mucociliary clearance plus increased bacterial adherence to respiratory mucosa damaged by viral infection. ${ }^{8}$ In addition, there are increasing data on a range of viral effects on innate immunity. ${ }^{8}$ Oliver et al demonstrated that rhinovirus infection inhibited alveolar macrophage inflammatory responses to lipopolysaccharide and lipoteichoic acid, bacterial cell wall components that are recognised by Toll-like receptors, and so could therefore inhibit effective immune responses to bacterial pathogens. ${ }^{9}$ The importance of recognising viral respiratory infections has been reinforced by data suggesting that antiviral agents improve survival for patients infected with seasonal or pandemic influenza. $^{4} 10$ Furthermore, immunisation with pneumococcal conjugate vaccine reduces hospitalisation for viral lower respiratory tract infection in children, highlighting the importance of bacterial-viral co-infection, and offering another strategy to reduce the burden of severe respiratory disease. ${ }^{11}$

Another discernible theme in Thorax publications since 2008 is improved definition of who is at risk of CAP. The incidence of CAP is highest in young children and the elderly, and globally CAP remains the major cause of mortality and also considerable morbidity in children under 5 years of age. ${ }^{12}{ }^{13}$ Co-morbidity or environmental exposures including malnutrition, HIV or biomass fuel exposure contribute to risk and severity of disease. Two studies published in Thorax quantified the risk of CAP in adults in more detail. In a very large retrospective report from Germany of 388406 patients, $45 \%$ of CAP cases were over 70 years old, ${ }^{14}$ and a paper from The Netherlands found that the incidence of lower respiratory tract infections approaches $1 \%$ in 85 year olds. ${ }^{15}$ Importantly, even in the elderly, $32 \%$ of lower respiratory tract infections were attributed to smoking and hence are potentially preventable. ${ }^{15}$ A further Thorax article described that exposure to metal fumes doubles mortality from $S$ pneumoniae or lobar pneumonia in working age men, ${ }^{16}$ making this another modifiable factor for preventing CAP. The contribution of pneumococcal serotype to severity of disease was shown by the association between septic shock complicating $S$ pneumoniae pneumonia with infections due to capsular serotype 3 strains (with an OR of 2.24). ${ }^{17}$ With recent improvements in the molecular epidemiology of infection and the advent of high-throughput genome sequencing, linking different infection phenotypes to specific bacterial pathogen strains will be an increasingly common theme in the future. Such information will also be important for the development of improved vaccines targeting particular bacterial strains associated with severe disease.

Several papers have also described risk groups for mycobacterial lung disease. This includes diabetes, which a recent Thorax paper estimated has a population-attributable risk of $11 \%$ of cases of TB in the UK, ${ }^{18}$ similar to that for HIV co-infection (assuming that the latter is tested for-which even in London was found to be inconsistent across TB services). ${ }^{19}$ The reported diabetes-TB interaction was most pronounced in Asians, a population who are also at increased risk of extrapulmonary TB. Kruijshaar and Abubakar showed that the proportion of non-pulmonary UK cases has increased between 1999 and 2006; and this largely arose in subjects born out of the country who had developed disease several years after arrival in the UK. ${ }^{20}$ In resource-constrained environments where there is a greater prevalence of TB, a link with exposure to biomass fuel is the subject of much debate. In a nested case-control study from rural India, it was estimated that over one-third of cases of pulmonary $\mathrm{TB}$ were attributable to exposure to biomass fuel. ${ }^{21}$ This report clearly has considerable implications for prevention of TB, but needs to be confirmed by other workers in other geographical settings.

The significance of isolation of non-tuberculous mycobacteria (NTM) from sputum is a common clinical dilemma. Data from The Netherlands described NTM isolations between 1999 and 2005 , and indicated that around one in four subjects with positive isolates satisfied American Thoracic Society/Infectious Diseases Society of America (ATS/IDSA) criteria for disease diagnosis $^{22}$ (a similar figure to reports from other centres). Although the numbers were small, they usefully categorised the clinical relevance of different species of pulmonary NTM isolates $^{22}$ (figure 1). Mycobacterium avium was one of the more common NTM species isolated, and caused disease in $50 \%$ of patients with positive respiratory cultures. Kikuchi et al presented Japanese data indicating that the risk of progressive disease with $M$ avium could be predicted by strain genotype. ${ }^{23}$ This observation may provide a method of risk stratifying NTM isolates, and thus assist clinicians in deciding whether to start treatment, and is another example linking genetic variation between strains of a bacterial pathogen to infection phenotype. A large French series of subjects infected with Mycobacterium xenopi delineated three patterns of disease: the classical cavitary form in patients with pre-existing lung damage, plus a nodular presentation in immunocompetent subjects and an acute pulmonary infiltrate with a higher mortality in immunosuppressed subjects. ${ }^{24}$ Overall mortality for patients fulfilling the ATS/IDSA criteria for $M$ xenopi infection was surprisingly high at $69 \%$ over 36 months, with $61 \%$ of deaths attributed to the $M$ xenopi infection rather than underlying disease, demonstrating that isolation of NTM can have serious implications. The paper also reported that rifamycin-containing regimens were associated with improved survival, a helpful observation as the optimum drug regimen for many common NTMs remains unclear. $^{25}$

The accurate microbiological diagnosis of respiratory infection is often difficult due to the poor reliability of the existing routine tests and the frequent requirement for bronchoscopy to obtain an appropriate sample. Amplification of pathogen nucleic acid

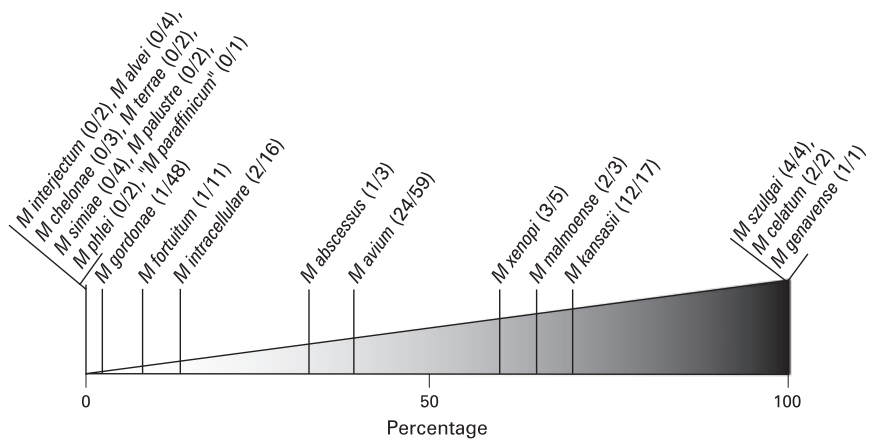

Figure 1 Clinical relevance of pulmonary non-tuberculous mycobacteria isolates, per species. $(x / y)$, number of patients who met the American Thoracic Society diagnostic criteria/total number of patients per species (reproduced from van Ingen et $\mathrm{a}^{22}$ ). 
by techniques such as PCR has the potential to considerably improve sensitivity and may not require invasive sampling. PCR for respiratory viruses is increasingly routinely available (perhaps in part stimulated by the H1N1 pandemic), and there is likely to be an increased emphasis on diagnosing respiratory viral infection. Pneumocystis jirovecii pneumonia (PCP) is an important complication in immunocompromised patients and requires prolonged treatment with often toxic therapy. As such there is a need for tests that can provide microbiological confirmation of the diagnosis in high-risk individuals. Huggett et al showed that PCR for $P$ jirovecii DNA in bronchoalveolar lavage fluid (BALF) can increase diagnostic sensitivity. ${ }^{26}$ However, such tests may be oversensitive, as $P$ jirovecii DNA can be detected in subjects unlikely to have PCP, with positive results in $8-68 \%$ (in HIVinfected subjects) with other final diagnoses. ${ }^{26} 27$ These results are presumed to represent asymptomatic colonisation with $P$ jirovecii, and illustrate the potential difficulty in interpreting the clinical relevance of a positive result using highly sensitive assays. It may be that quantification of pathogen load using realtime PCR can distinguish colonisation from infection. ${ }^{26} 27$ Furthermore, detection of colonisation could be beneficial as this might identify subjects at high risk of developing PCP. Further research is necessary to define the role of PCR in PCP, as well as other common non-viral respiratory infections.

The recognition of a typical host response to a pathogen is an alternative approach to infection diagnosis. For example, chest radiographic changes of consolidation combined with evidence of an acute inflammatory response such as a raised temperature or CRP level is highly suggestive of CAP. However, the high incidence of alternative pathologies with a similar presentation makes recognition of ventilator-acquired pneumonia (VAP) considerably more difficult. Conway Morris et al investigated whether measuring BALF cytokine levels might assist in the identification of VAP. ${ }^{28}$ Using a definition of VAP as $>10^{4}$ pathogen colony-forming units/ml of BALF they found that BALF interleukin $1 \beta$ (IL-1 $\beta$ ) and IL-8 levels could distinguish subjects with VAP from non-infective causes. These data may lead to a diagnostic test for VAP using biomarkers that appears to be at least partly independent of the causative pathogen. In the future, technologies such as proteomics and transcriptional arrays could be used to simultaneously measure a large range of host protein and RNA responses as biomarkers, potentially improving diagnostic specificity and sensitivity and perhaps even identifying host response 'signatures' specific for particular pathogens. Another measure of host immune response are interferon gamma release assays (IGRA) for diagnosing $M$ tuberculosis infection, which have generated many publications in Thorax over the past 3 years. Discordant results with different tests and a high failure rate in some subjects such as children in whom they might be of most use potentially limit their utility. ${ }^{2930}$ However, recent Thorax publications do suggest that IGRAs may be useful for contact tracing exposed individuals in TB endemic areas with high background rates of HIV infection, ${ }^{31}$ and play a role in new-entrant screening in lower incidence settings. ${ }^{32}$ Furthermore, a meta-analysis confirms their potential for identifying latent $\mathrm{TB}$ infection. ${ }^{33}$ In contrast to latent TB infection, blood IGRAs are not particularly helpful for diagnosing active TB disease. However, two papers have suggested that using bronchoalveolar lavage samples for commercially available IGRA or an alternative antigen stimulation test based on flow cytometry can rapidly identify cases of smear-negative pulmonary TB. ${ }^{34} 35$ These organ-specific approaches for TB antigen tests could theoretically be extended to additional potential sites of infection such as lymph node aspirates, pleural fluid ${ }^{36}$ or cerebrospinal fluid (CSF). In combination with modern microbiological techniques this may provide a reasonably simple and enhanced diagnostic approach to promptly confirm extrapulmonary disease in subjects at risk of active TB.

Publications on clinical scores for adult patients with CAP and other lung infections form the biggest subcategory of lung infection papers published in Thorax, and there has been considerable interest in using biomarkers as adjuncts for risk stratification. Clinical scores such as the Pneumonia Severity Index (PSI) or the CURB65 scale are widely used in clinical practice and for research to assess severity in patients with CAP. They have been validated by numerous publications including the recent large German study. ${ }^{14}$ However, while PSI and CURB65 scales both have good negative predictive values for poor outcomes, they are less efficient at predicting high-risk patients, as illustrated by two meta-analyses published in Thorax in 2010 (and discussed in the accompanying editorial). ${ }^{37-39}$ PSI and CURB65 scoring scales are also less accurate in elderly patients. ${ }^{40}$ This has led to the development of additional CAP severity scoring systems such as the modified ATS/IDSA minor criteria, validated in a large study published in Thorax in $2009,{ }^{41}$ as well as research into the role of a wide range of biomarkers including specific cytokines, CRP, pro-calcitonin, pro-atrial naturietic peptide and pro-vasopressin. Biomarkers have been investigated in patients with CAP for their ability to improve the prediction of disease severity, 90 day mortality, failure to respond to treatment and the development of complications such as complex pleural effusions. ${ }^{42-46}$ Several studies indicated that levels of the routinely available biomarker CRP improved the prediction of mortality, identified patients at risk of complicated parapneumonic effusion or treatment failure, and could be used to monitor treatment response, ${ }^{43} 44$ 46-48 suggesting that CRP levels could be used to direct a range of management decisions in patients with CAP. ${ }^{42}$ In addition new clinical scores have been suggested for identifying patients with CAP at risk of complex pleural effusions ${ }^{43}$ and predict 90 day mortality, ${ }^{47}$ as well as to pinpoint high-risk patients with PCP ${ }^{49}$ and define the radiological severity of pulmonary TB and identify those at risk of poor response to treatment ${ }^{50}$ (table 1).

In contrast to papers on clinical scoring and risk factors, there have been very few studies in Thorax over the past 3 years investigating how infectious lung disease should be actually managed. For CAP some data have been published suggesting that in the UK patients under the care of a respiratory physician with non-severe CAP will have a shorter length of stay in hospital (by a mean of 1.3 days), ${ }^{51}$ and that using urine antigen results to limit empirical antibiotic therapy is not beneficial. ${ }^{52}$ However, intervention studies in CAP (eg, assessing whether using biomarkers to guide antibiotic duration ${ }^{53}$ and/or for early identification of patients at risk of severe complications actually improves clinical outcomes) will require larger numbers of patients to detect the probably relatively small differences in efficacy between management strategies. As hospitalisation with CAP is a common clinical problem with significant associated mortality and morbidity, the necessary multicentre trials should be possible to organise and fund. Non-cystic fibrosis (CF) bronchiectasis is another area that requires large multicentre trials to evaluate efficacy of different management options. Although non-CF bronchiectasis affects an estimated minimum of 30000 people in the UK, there has been a surprising lack of research papers published in Thorax or other clinical journals on this disease. Thorax articles on non-CF bronchiectasis over the past 3 years are limited to a review, an editorial to accompany the 
Table 1 New clinical scoring scales published in Thorax 2008-2010

\begin{tabular}{|c|c|c|c|}
\hline Infection syndrome & Description & Discriminating factors & Author \\
\hline Risk of CPE in CAP & $\begin{array}{l}6 \text { point score: score } 2+\text { positive/negative predictive } \\
\text { values } 17.7 \% / 98.5 \%\end{array}$ & $\begin{array}{l}\text { Albumin }<30 \mathrm{~g} / \mathrm{l}, \mathrm{CRP}>100 \mathrm{mg} / \mathrm{l} \text {, platelet count } \\
>400 \times 10^{9} / \mathrm{l}, \mathrm{Na}^{+}<130 \mathrm{mmol} / \mathrm{l} \text {, injecting drug use, } \\
\text { alcohol overuse (all }+1 \text { ), COPD (protective, }-1 \text { ) }\end{array}$ & Chalmers $^{43}$ \\
\hline CAP 90 day mortality & $\begin{array}{l}\text { Weighted score: } 0-2,0.7 \% ; 3-7,3.5 \% ;>7,17.2 \% \\
\text { mortality }\end{array}$ & $\begin{array}{l}\text { Baseline functional status (Katz index), co-morbidities } \\
\text { (Charlson index), CURB score }\end{array}$ & Capelastegui $^{47}$ \\
\hline PCP & $\begin{array}{l}6 \text { point score for mortality risk (score } 0-1,4 \% ; 2-3 \text {, } \\
12 \% ; 4-5,48 \% \text { ) }\end{array}$ & $\begin{array}{l}\text { Age }>40 \text {, albumin }<30 \mathrm{~g} / \mathrm{l} \text {, bilirubin }>6 \mathrm{mg} / \mathrm{l} \text {, } \\
\text { alveolar-arterial oxygen gradient }>50 \mathrm{~mm} \mathrm{Hg} \text {, } \\
\text { intravenous drug use (all }+1 \text { ) }\end{array}$ & $\mathrm{Fei}^{49}$ \\
\hline $\begin{array}{l}\text { Pulmonary TB, sputum } \\
\text { smear positive }\end{array}$ & $\begin{array}{l}\text { Prediction of treatment response from radiology scoring: } \\
\text { score }>71,80 \% \text { sensitive/ } 68 \% \text { specific persistent } \\
\text { smear-positive sputum after } 2 \text { months treatment }\end{array}$ & $\begin{array}{l}\text { Score }=\text { proportion of lung affected }(\%)+40 \text { if cavitation } \\
\text { present on baseline frontal chest radiograph }\end{array}$ & Ralph $^{50}$ \\
\hline
\end{tabular}

CAP, community acquired pneumonia; CPE, complex pleural effusions; CRP, C-reactive protein; PCP, Pneumocystis jirovecii pneumonia; TB, tuberculosis.

publication of the British Thoracic Society guidelines, ${ }^{54}$ and a single research letter. ${ }^{55}$ The latter was a small but much needed trial suggesting that prophylactic treatment with nebulised colomycin reduced sputum volume, hospital admissions and exacerbation frequency in patients with non-CF bronchiectasis compared with historical controls. These data support the findings of a recently published controlled trial of nebulised gentamicin, ${ }^{56}$ and hopefully will lead to larger trials to provide essential data to support management of non-CF bronchiectasis. Intervention trials in CF and non-CF bronchiectasis (and even chronic obstructive pulmonary disease (COPD)) should also benefit from recently developed techniques for identifying and quantifying bacterial colonisation of the airways by amplification of DNA encoding 16S RNA or even direct sequencing of bacterial DNA.

Vaccination against infectious disease is one of the most effective public health interventions, and several recent papers in Thorax have provided data on the effects of vaccination against lung infection. A large study analysed the effects of influenza and S pneumoniae vaccination in nearly 180000 patients with COPD. The authors demonstrated a $41 \%$ reduction in all-cause mortality for patients vaccinated against influenza, ${ }^{57}$ reinforcing that all patients with COPD should be offered annual influenza vaccination. In contrast, despite the increased risk of CAP in COPD, vaccination against $S$ pneumoniae had no effect on mortality. ${ }^{57}$ The existing adult $S$ pneumoniae vaccine consists of polyvalent unconjugated capsular polysaccharide antigens and, although it protects against systemic infection, may be poorly immunogenic in the elderly and has poor efficacy at preventing pneumonia. ${ }^{58}$ The recently introduced childhood $S$ pneumoniae conjugate vaccine contains capsular antigens conjugated to a carrier protein, and protects against pneumonia and invasive disease in children. The efficacy of the conjugated vaccine in adults is not known, but trial data will be available shortly and may alter vaccination policy for adults at risk of CAP. Moreover, with widespread vaccination of children, a reduction in the burden of adult disease may occur due to the reduction in prevalence of circulating vaccine serotype $S$ pneumoniae. ${ }^{59}$

Although BCG vaccination against $\mathrm{TB}$ has been used for 90 years, two articles and an editorial published in Thorax in 2010 offered further insight on its efficacy. ${ }^{60-62}$ Eriksen et al found that for UK children exposed to a smear-positive index case, prior BCG vaccination reduced the risk of acquisition of infection, as measured by a positive IGRA response. ${ }^{60}$ Jeremiah et al observed that subjects in Tanzania with pulmonary TB without previous BCG vaccination were more likely to be sputum positive for acid-fast bacilli after 2 months of treatment than those who had received BCG. ${ }^{61}$ These data suggest BCG vaccination may enhance host immunity to $\mathrm{TB}$ both in the initial infective period and during actual disease. How this occurs, and if it is a real effect, remain uncertain. Mycobacterium vaccae immunotherapy did not confer any such treatment benefit in the recent BTS NTM trial, ${ }^{25}$ although a live attenuated bacterial vaccine approach could still be potentially effective in boosting immunological responses to new vaccines as well as in the management of drug-resistant TB. ${ }^{63}$

Although the last 3 years have seen substantial research related to respiratory infectious disease, the research output in this area has been relatively low considering the massive impact of viral, fungal and bacterial lung infection on respiratory health. We do not think this reflects a publication bias against infection, but more the lack of active research in this field despite the major areas where further clinical or translational research is badly required. These include better diagnostics for childhood and adult pneumonia, controlled trials of therapies for non-CF bronchiectasis, showing how biomarkers and rapid diagnostics can improve the management of not only CAP but also hospitalacquired pneumonia and VAP, and the role of the conjugated $S$ pneumoniae vaccine in preventing CAP and its effects on the epidemiology and aetiology of pneumonia. In addition, there is a strong need for better methods for diagnosing active TB infection, finding correlates of protection for $\mathrm{TB}$ infection and disease, rapid identification of causative pathogens for immunosuppressed patients presenting with pneumonia, and more detailed descriptions of the airway microbiome during health and in a variety of disease conditions such as HIV infection, COPD and bronchiectasis. We also need a better understanding of the long-term impact of infectious diseases such as TB on individual health status after apparent cure, ${ }^{64}$ as well as the healthcare and societal costs associated with different treatment stratagems. ${ }^{65}$ Research in these areas plus advances in microbiology and assessing host-pathogen interactions will hopefully lead to substantial improvements in the management of patients with lung infection, and we look forward to future publications in Thorax addressing these questions.

Funding JSB and MCIL work at UCLH/UCL which receives a proportion of funding from the Department of Health's NIHR Biomedical Research Centre's funding scheme.

Competing interests None.

Contributors This article was conceived and written by all three authors.

Provenance and peer review Commisioned; internally peer reviewed.

\section{REFERENCES}

1. Smith GJ, Vijaykrishna D, Bahl J, et al. Origins and evolutionary genomics of the 2009 swine-origin H1N1 influenza A epidemic. Nature 2009;459:1122-5.

2. Miller $\mathbf{E}$, Hoschler $K$, Hardelid $P$, et al. Incidence of 2009 pandemic influenza A H1N1 infection in England: a cross-sectional serological study. Lancet 2010;375:1100-8.

3. Fajardo-Dolci G, Gutierrez-Vega R, Arboleya-Casanova $\mathrm{H}$, et al. Clinical characteristics of fatalities due to influenza A (H1N1) virus in Mexico. Thorax 2010;65:505-9.

4. Dunning J, Openshaw PJ. Impact of the 2009 influenza pandemic. Thorax 2010;65:471-2. 
5. Nguyen-Van-Tam JS, Openshaw PJ, Hashim A, et al; Influenza Clinical Information Network (FLU-CIN). Risk factors for hospitalisation and poor outcome with pandemic A/H1N1 influenza: United Kingdom first wave (May-September 2009). Thorax 2010;65:645-51.

6. Thickett DR, Griffiths M, Perkins GD, et al. Hot off the breath: the 2009 H1N1 flu pandemic may be gone but should not be forgotten. Thorax 2010:65:855-6.

7. Jennings LC, Anderson TP, Beynon KA, et al. Incidence and characteristics of viral community-acquired pneumonia in adults. Thorax 2008;63:42-8.

8. McCullers JA. Insights into the interaction between influenza virus and pneumococcus. Clin Microbiol Rev 2006;19:571-82.

9. Oliver BG, Lim S, Wark $P$, et al. Rhinovirus exposure impairs immune responses to bacterial products in human alveolar macrophages. Thorax 2008;63:519-25.

10. Lee $\mathbf{N}$, Choi KW, Chan PK, et al. Outcomes of adults hospitalised with severe influenza. Thorax 2010;65:510-15.

11. Madhi SA, Klugman KP; Vaccine Trialist Group. A role for Streptococcus pneumoniae in virus-associated pneumonia. Nat Med 2004;10:811-13.

12. O'Brien KL, Wolfson LJ, Watt JP, et al; Hib and Pneumococcal Global Burden of Disease Study Team. Burden of disease caused by Streptococcus pneumoniae in children younger than 5 years: global estimates. Lancet 2009;374:893-902.

13. Black RE, Cousens S, Johnson HL, et al: Child Health Epidemiology Reference Group of WHO and UNICEF. Global, regional, and national causes of child mortality in 2008: a systematic analysis. Lancet 2010;375:1969-87.

14. Ewig S, Birkner N, Strauss R, et al. New perspectives on community-acquired pneumonia in 388406 patients. Results from a nationwide mandatory performance measurement programme in healthcare quality. Thorax 2009;64:1062-9.

15. Sliedrecht A, den Elzen WP, Verheij TJ, et al. Incidence and predictive factors of lower respiratory tract infections among the very elderly in the general population The Leiden 85-plus Study. Thorax 2008:63:817-22.

16. Palmer KT, Cullinan $P$, Rice $S$, et al. Mortality from infectious pneumonia in metal workers: a comparison with deaths from asthma in occupations exposed to respiratory sensitisers. Thorax 2009;64:983-6.

17. Garcia-Vidal C, Ardanuy C, Tubau F, et al. Pneumococcal pneumonia presenting with septic shock: host- and pathogen-related factors and outcomes. Thorax 2010;65:77-81.

18. Walker C, Unwin N. Estimates of the impact of diabetes on the incidence of pulmonary tuberculosis in different ethnic groups in England. Thorax 2010;65:578-81.

19. Rodger AJ, Story A, Fox Z, et al; London Tuberculosis Nurses Network. HIV prevalence and testing practices among tuberculosis cases in London: a missed opportunity for HIV diagnosis? Thorax 2010;65:63-9.

20. Kruijshaar ME, Abubakar I. Increase in extrapulmonary tuberculosis in England and Wales 1999-2006. Thorax 2009;64:1090-5.

21. Kolappan C, Subramani R. Association between biomass fuel and pulmonary tuberculosis: a nested case-control study. Thorax 2009;64:705-8.

22. van Ingen J, Bendien SA, de Lange WC, et al. Clinical relevance of non-tuberculous mycobacteria isolated in the Nijmegen-Arnhem region, The Netherlands. Thorax 2009;64:502-6

23. Kikuchi T, Watanabe A, Gomi K, et al. Association between mycobacterial genotypes and disease progression in Mycobacterium avium pulmonary infection. Thorax 2009;64:901-7.

24. Andrejak C, Lescure FX, Pukenyte E, et al; Xenopi Group. Mycobacterium xenopi pulmonary infections: a multicentric retrospective study of 136 cases in north-east France. Thorax 2009;64:291-6.

25. Jenkins PA, Campbell IA, Banks J, et al. Clarithromycin vs ciprofloxacin as adjuncts to rifampicin and ethambutol in treating opportunist mycobacterial lung diseases and an assessment of Mycobacterium vaccae immunotherapy. Thorax

2008:63:627-34

26. Huggett JF, Taylor MS, Kocjan G, et al. Development and evaluation of a real-time PCR assay for detection of Pneumocystis jirovecii DNA in bronchoalveolar lavage fluid of HIV-infected patients. Thorax 2008;63:154-9.

27. Davis JL, Welsh DA, Beard CB, et al. Pneumocystis colonisation is common among hospitalised HIV infected patients with non-Pneumocystis pneumonia. Thorax 2008;63:329-34

28. Conway Morris A, Kefala K, Wilkinson TS, et al. Diagnostic importance of pulmonary interleukin- $1 \beta$ and interleukin- 8 in ventilator-associated pneumonia. Thorax 2010;65:201-7

29. Hesseling AC, Mandalakas AM, Kirchner HL, et al. Highly discordant T cell responses in individuals with recent exposure to household tuberculosis. Thorax 2009;64:840-6

30. Lucas M, Nicol P, McKinnon E, et al. A prospective large-scale study of methods for the detection of latent Mycobacterium tuberculosis infection in refugee children. Thorax 2010;65:442-8.

31. Mutsvangwa J, Millington KA, Chaka $\mathrm{K}$, et al. Identifying recent Mycobacterium tuberculosis transmission in the setting of high HIV and TB burden. Thorax 2010;65:315-20.

32. Moore-Gillon J, Davies PD, Ormerod LP. Rethinking TB screening: politics, practicalities and the press. Thorax 2010;65:663-5.

33. Chang KC, Leung CC. Systematic review of interferon- $\gamma$ release assays in tuberculosis: focus on likelihood ratios. Thorax 2010;65:271-6.

34. Dheda K, van Zyl-Smit RN, Meldau R, et al. Quantitative lung T cell responses aid the rapid diagnosis of pulmonary tuberculosis. Thorax 2009:64:847-53.

35. Breen RA, Barry SM, Smith CJ, et al. Clinical application of a rapid lung-orientated immunoassay in individuals with possible tuberculosis. Thorax 2008;63:67-71.
36. Dheda K, van Zyl-Smit RN, Sechi LA, et al. Utility of quantitative T-cell responses versus unstimulated interferon-\{gamma\} for the diagnosis of pleural tuberculosis. Eur Respir J 2009;34:1118-26.

37. Ewig S, Torres A. Severity scores for CAP. 'Much workload for the next bias'. Thorax 2010;65:853-5.

38. Chalmers JD, Singanayagam A, Akram AR, et al. Severity assessment tools for predicting mortality in hospitalised patients with community-acquired pneumonia. Systematic review and meta-analysis. Thorax 2010;65:878-83.

39. Loke YK, Kwok CS, Niruban A, et al. Value of severity scales in predicting mortality from community-acquired pneumonia: systematic review and meta-analysis. Thorax 2010;65:884-90.

40. Chen JH, Chang SS, Liu JJ, et al. Comparison of clinical characteristics and performance of pneumonia severity score and CURB-65 among younger adults, elderly and very old subjects. Thorax 2010;65:971-7.

41. Phua J, See KC, Chan YH, et al. Validation and clinical implications of the IDSA/ATS minor criteria for severe community-acquired pneumonia. Thorax 2009;64:598-603.

42. Brown JS. Biomarkers and community-acquired pneumonia. Thorax 2009;64:556-8.

43. Chalmers JD, Singanayagam A, Murray MP, et al. Risk factors for complicated parapneumonic effusion and empyema on presentation to hospital with community-acquired pneumonia. Thorax 2009;64:592-7.

44. Menendez R, Cavalcanti M, Reyes S, et al. Markers of treatment failure in hospitalised community acquired pneumonia. Thorax 2008;63:447-52.

45. Kruger S, Ewig S, Kunde J, et al. Pro-atrial natriuretic peptide and pro-vasopressin for predicting short-term and long-term survival in community-acquired pneumonia: results from the German Competence Network CAPNETZ. Thorax 2010;65:208-14

46. Menendez R, Martinez R, Reyes S, et al. Stability in community-acquired pneumonia: one step forward with markers? Thorax 2009;64:987-92.

47. Capelastegui A, Espana PP, Quintana JM, et al. Development of a prognostic index for 90-day mortality in patients discharged after admission to hospital for community-acquired pneumonia. Thorax 2009;64:496-501.

48. Chalmers JD, Singanayagam A, Hill AT. C-reactive protein is an independent predicto of severity in community-acquired pneumonia. Am J Med 2008;121:219-25.

49. Fei MW, Kim EJ, Sant CA, et al. Predicting mortality from HIV-associated Pneumocystis pneumonia at illness presentation: an observational cohort study. Thorax 2009;64:1070-6.

50. Ralph AP, Ardian M, Wiguna A, et al. A simple, valid, numerical score for grading chest $\mathrm{x}$-ray severity in adult smear-positive pulmonary tuberculosis. Thorax 2010;65:863-9.

51. Bewick T, Cooper VJ, Lim WS. Does early review by a respiratory physician lead to a shorter length of stay for patients with non-severe community-acquired pneumonia? Thorax 2009;64:709-12.

52. Falguera M, Ruiz-Gonzalez A, Schoenenberger JA, et al. Prospective, randomised study to compare empirical treatment versus targeted treatment on the basis of the urine antigen results in hospitalised patients with community-acquired pneumonia. Thorax 2009;65:101-6.

53. Christ-Crain M, Stolz D, Bingisser R, et al. Procalcitonin guidance of antibiotic therapy in community-acquired pneumonia: a randomized trial. Am J Respir Crit Care Med 2006;174:84-93.

54. Pasteur MC, Bilton D, Hill AT; British Thoracic Society Non-CF Bronchiectasis Guideline Group. British Thoracic Society guideline for non-CF bronchiectasis. Thorax 2010;65:577.

55. Dhar R, Anwar GA, Bourke SC, et al. Efficacy of nebulised colomycin in patients with non-cystic fibrosis bronchiectasis colonised with Pseudomonas aeruginosa. Thorax 2010;65:553

56. Murray MP, Govan JR, Doherty CJ, et al. A randomized controlled trial of nebulized gentamicin in non-cystic fibrosis bronchiectasis. Am J Respir Crit Care Med 2011:183:491-9.

57. Schembri S, Morant S, Winter JH, et al. Influenza but not pneumococcal vaccination protects against all-cause mortality in patients with COPD. Thorax 2009;64:567-72

58. Huss $\mathbf{A}$, Scott $P$, Stuck $A E$, et al. Efficacy of pneumococcal vaccination in adults: a meta-analysis. CMAJ 2009:180:48-58.

59. Lexau CA, Lynfield R, Danila R, et al; Active Bacterial Core Surveillance Team. Changing epidemiology of invasive pneumococcal disease among older adults in the era of pediatric pneumococcal conjugate vaccine. JAMA 2005:294:2043-51.

60. Eriksen J, Chow JY, Mellis V, et al. Protective effect of BCG vaccination in a nursery outbreak in 2009: time to reconsider the vaccination threshold? Thorax 2010;65:1067-71

61. Jeremiah K, Praygod G, Faurholt-Jepsen D, et al. BCG vaccination status may predict sputum conversion in patients with pulmonary tuberculosis: a new consideration for an old vaccine? Thorax 2010;65:1072-6.

62. Lalvani A, Sridhar S. BCG vaccination: 90 years on and still so much to learn. Thorax 2010;65:1036-8.

63. Abubakar I, Moore J, Drobniewski F, et al. Extensively drug-resistant tuberculosis in the UK: 1995 to 2007. Thorax 2009;64:512-15.

64. Ross J, Ehrlich Rl, Hnizdo $\mathrm{E}$, et al. Excess lung function decline in gold miners following pulmonary tuberculosis. Thorax 2010;65:1010-15.

65. Aspler A, Long R, Trajman A, et al. Impact of treatment completion, intolerance and adverse events on health system costs in a randomised trial of 4 months rifampin or 9 months isoniazid for latent TB. Thorax 2010;65:582-7. 